\title{
UJI SIFAT FISIK TABLET SALUT ENTERIK KALIUM DIKLOFENAK GENERIK DAN GENERIK BERMEREK YANG BEREDAR DI APOTEK KECAMATAN SIAK HULU
}

\author{
Benni Iskandar ${ }^{*}$, Iga Susanti ${ }^{1}$ \\ ${ }^{1}$ Sekolah Tinggi Ilmu Farmasi Riau, Pekanbaru 28423 \\ 1*Email: benniiskandar@stifar-riau.ac.id
}

\begin{abstract}
ABSTRAK
Kalium diklofenak merupakan obat Antiinflamasi non steroid yang banyak digunakan dan tersedia dalam bentuk tablet generik dan generik bermerek. Penelitian ini bertujuan untuk mengetahui sifat fisik antara tablet salut enterik kalium diklofenak generik dan generik bermerek yang beredar di apotek Kecamatan Siak Hulu. Jenis penelitian ini merupakan eksperimental dengan pemilihan sampel secara random dan purposive sampling. Pengujian dilakukan terhadap 2 sampel tablet salut enterik kalium diklofenak generik dan 1 sampel tablet salut enterik kalium diklofenak generik bermerek. Uji mutu fisik yang dilakukan seperti keseragaman ukuran, kekerasan, kerapuhan, ketahanan, keseragaman bobot, dan waktu hancur. Berdasarkan hasil pengujian semua tablet salut enterik Kalium diklofenak generik dan generik bermerek memenuhi persyaratan menurut Farmakope Indonesia dan literature lainnya
\end{abstract}

Kata Kunci : Sifat fisik, Kalium Diklofenak, Tablet salut enterik, Generik, Generik bermerek.

\begin{abstract}
Diclofenac potassium is a non-steroidal anti-inflammatory drug that is widely used and available in the form of generic tablets and branded generics. This study aims to determine the physical properties between generic and generic branded diclofenac enteric coated tablets circulated at the pharmacy in Siak Hulu District. This type of research is experimental with random sample selection and purposive sampling. Tests were carried out on 2 samples of generic enteric diclofenac enteric coated tablets and 1 sample of generic enteric diclofenac enteric coated tablets. Physical quality tests are carried out such as uniformity of size, hardness, friability, endurance, uniformity of weights, and disintegration time. Based on the results of testing all generic and generic branded potassium enteric coated tablets meet the requirements according to Indonesian Pharmacopoeia and other literature.
\end{abstract}

Keywords: Physical properties, Potassium Diclofenac, Enteric coated tablets, Generic, Generics branded.

\section{PENDAHULUAN}

Obat merupakan unsur yang sangat penting dalam upaya penyelenggaraan kesehatan. Sebagian besar intervensi medik menggunakan obat, oleh karena itu obat harus tersedia pada saat diperlukan dalam jenis dan jumlah yang cukup, berkhasiat nyata dan berkualitas baik (Sambara, 2007). Obat beredar dalam berbagai macam bentuk sediaan, salah satunya adalah obat dalam sediaan tablet. Tablet merupakan bentuk sediaan yang paling banyak digunakan, karena memiliki beberapa keuntungan diantaranya ketepatan dosis, mudah cara pemakaiannya, stabil dalam penyimpanan, mudah dalam transportasi dan dari segi ekonomi relatif murah dibanding dengan bentuk sedian obat lainnya lainnya (Chaerunnisa dan soeryati, 2009).

Salah satu obat dalam sediaan tablet yang beredar di pasaran adalah tablet Kalium diklofenak. Merupakan golongan Anti Inflammatory Non Steroid (AINS) mengandung garam kalium dari diklofenak, ion sodium dari sodium diklofenak diganti dengan ion kalium, sehingga mula kerja kalium diklofenak lebih cepat dari natrium diklofenak (Goodman and Gilman, 2007). Kalium diklofenak banyak digunakan oleh masyarakat dalam kondisi menderita inflamasi baik pada inflamasi ringan seperti radang gusi, hingga gejala inflamasi yang berat seperti rheumatoid arthitis. Di Indonesia, Penyakit sendi merupakan penyakit tidak menular dengan pravelensi tertinggi pada orang dewasa dan lansia (Anonim, 2007).
Pada umumnya masyarakat lebih suka menggunakan produk obat generik bermerek/produk dengan nama dagang dibanding produk obat generik. Hal ini disebabkan banyak masyarakat yang tidak mengerti tentang obat. Pada kenyataannya obat generik harus memenuhi standar yang ketat seperti obat generik bermerek. Obat generik dan generik bermerek memiliki aspek formulasi yang berbeda tergantung dari perusahaan farmasi yang memproduksi, aspek formulasi ini meliputi formula, metode, proses, peralatan dan pengemas (Shargel, 2005). Sediaan tablet mempunyai beberapa persyaratan antara lain uji mutu fisik. Mutu dijadikan dasar acuan untuk menetapkan kebenaran khasiat dan keamanan. Mutu suatu sediaan obat dapat dilihat dari berbagai aspek antara lain aspek teknologi yang meliputi stabilitas fisik dan kimia, sediaan tablet harus memenuhi kriteria yang dipersyaratkan oleh Farmakope (Siregar, 2010).

Pada penelitian yang telah dilakukan uji mutu fisik tablet salut enterik natrium diklofenak antara produk generik dan generik bermerek, hasil penelitian terdapat perbedaan fisik antara tablet natrium diklofenak generik dan generik bermerek pada keseragaman bobot tablet generik 1,32\% sedangkan tablet generik bermerek $0,42 \%$ dan uji waktu hancur tablet generik $\pm 2,68$ menit dan tablet generik bermerek $\pm 1,98$ menit, sedangkan untuk uji kekerasan dan kerapuhan keduanya berbeda tetapi tidak signifikan (Masruriati, 2013).

Evaluasi tablet perlu dilakukan untuk mengetahui sifat fisika, kimia, dan biologi sediaan tersebut. Sifat-sifat ini dapat menggambarkan sifat fisik 
dari tablet atau formulasi tablet serta kondisi penyimpanan kemungkinan tekanan atau keadaan lingkungan luar. Berdasarkan hal itu peneliti tertarik untuk melakukan uji sifat fisik tablet salut enterik kalium diklofenak generik dan generik bermerek yang beredar dikecamatan Siak Hulu dan disesuaikan dengan persyaratan sifat fisik yang ditetapkan Farmakope Indonesia.

\section{METODE PENELITIAN}

\section{Alat dan Bahan}

Alat : uji keseragaman bobot (timbangan Analitik), Alat uji keseragaman Ukuran (jangka sorong), alat uji kerapuhan tablet (Friabilator Roche), dan uji ketahanan tablet (Abriation Tester), alat uji kekerasan (Hardness Tester) Stokes Monsanto dan alat uji waktu hancur (Desintegrator Tester), dan Beker glass.

Bahan : Kalium Diklofenak $50 \mathrm{mg}$ generik tablet A, tablet B, dan Generik bermerek tablet C, HCL 0,06 N, Larutan dapar phosfat (pH 6,8), Aquadest.

\section{Cara Kerja}

\section{Pemilihan Sampel}

Pemilihan sampel dilakukan dengan metode random dan purposive sampling yaitu pemilihan sampel dilakukan secara acak. Sampel yang digunakan yaitu tablet Kalium diklofenak $50 \mathrm{mg}$ generik diproduksi dengan 2 pabrik yang berbeda no. batch yang sama, yaitu: tablet A No. batch 49F0259 dan tablet B no. batch HTDP5A82014, sedangkan untuk tablet Kalium diklofenak generik bermerek yaitu tablet C No. batch A7C514B.

\section{Keseragaman Bobot}

1. Menimbang 10 tablet satu per satu.

2. Hitung bobot rata-rata

3. Hitung persentase penyimpangan bobot

4. Menghitung nilai simpangan baku relatif (SBR)

Persyaratan dipenuhi jika jumlah zat aktif dari masing-masing dari 10 satuan terletak antara 85,0\% hingga $115,0 \%$ dan simpangan baku relatif kurang atau sama dengan $6,0 \%$. Jika 1 satuan terletak diluar rentang $85,0 \%$ hingga $115,0 \%$ dan tidak ada satuan terletak antara rentang $75,0 \%$ hingga $125,0 \%$ atau jika simpangan baku relatif lebih besar dari $6,0 \%$ atau jika kedua kondisi tidak dipenuhi, lakukan uji 20 satuan tambahan. Persyaratan dipenuhi jika tidak lebih dari 1 satuan dari 30 terletak diluar rentang 85,0\% hingga $115,0 \%$ dan tidak ada satuan yang terletak diluar rentang $75,0 \%$ hingga $125,0 \%$ dan simpangan baku relatif dari 30 satuan sediaan tidak lebih dari 7,8\% (Anonim, 1995).

\section{Keseragaman Ukuran}

Sebanyak 10 tablet diukur diameter dan tebal masing-masing dengan menggunakan jangka sorong.
Kemudian cari rata-rata keseluruhan tablet yang merupakan diameter tablet yang dimadsud. Menurut farmakope menetapkan bentuk tablet kecuali dinyatakan lain, diameter tidak boleh dari $1 \frac{1}{3}$ dan tidak lebih dari 3 kali tebal tablet (Anonim, 1979).

\section{Kekerasan Tablet}

Diambil 10 tablet secara acak, letakkan tablet pada diantara pengapit tetap dengan plat datar yang diam, tablet dijepit dengan memutar alat penekan. Angka yang di tunjukkan oleh jarum pada skala dinyatakan sebagai titik nol kemudian alat penekan diputar kembali sampai tablet retak atau pecah. Catat skala yang terukur, kekerasan tablet adalah selisih skala terukur saat tablet pecah dengan skala yang dianggap sebagai titik nol, jadi persyaratan untuk kekerasan tablet lepas tunda yaitu antara $10-20 \mathrm{~kg} / \mathrm{cm}^{2}$ (Hadisoewignyo dan Fudholi, 2016).

\section{Kerapuhan (Friabilitas) Tablet Kalium Diklofenak}

Dilakukan terhadap 20 tablet. Tablet dibersihkan terlebih dahulu kemudian ditimbang (Wo), setelah itu dimasukkan kedalam alat (Friabilator Rosche) dan lakukan pemutaran sebanyak 100x putaran kecepatan 25 rpm selama 4 menit, kemudian tablet dikeluarkan, tablet dibersihkan dan ditimbang kembali (Wt) lalu dihitung $\%$ friabilitas (Kerapuhan) tablet dengan menggunakan rumus :

$$
\% \text { friabilitas }=\frac{w_{o-w t}}{w_{a}} \times 100 \%
$$

Persen Friabilitas yang baik tidak melebihi adalah $<1 \%$ (Syukri, 2018).

\section{Ketahanan (Friksibilitas) Tablet Kalium Diklofenak}

Dilakukan terhadap 20 tablet. Tablet dibersihkan terlebih dahulu kemudian ditimbang (Wo), setelah itu dimasukkan kedalam alat (Abration tester) dan lakukan pemutaran sebanyak 100x putaran kecepatan $25 \mathrm{rpm}$ selama 4 menit, kemudian tablet dikeluarkan, tablet dibersihkan dan ditimbang kembali (Wt) lalu dihitung $\%$ friksibilitas (Ketahanan) tablet dengan menggunakan rumus :

$$
\% \text { friabilitas }=\frac{w_{0}-w_{t}}{w_{0}} \times 100 \%
$$

Persen Friksibilitas yang baik tidak melebihi adalah $<1 \%$ ( Siregar, 2010).

\section{Waktu Hancur Tablet Salut enterik}

Ambil 6 tablet secara acak, HCL 0,06 N sebagai media dimasukkan ke dalam gelas piala $800 \mathrm{ml}$, atur suhunya $37^{\circ} \mathrm{C} \pm 2^{\circ} \mathrm{C}$. Masukkan masing-masing 1 tablet ke dalam tabung alat uji waktu hancur, masukkan cakram pada masing-masing tabung, kemudian 
nyalakan tombol start pada alat untuk menaik dan turunkan alat, dan tidak meperlihatkan adanya keretakan atau hancur pada tablet selama 1 jam. Angkat kerajang, bersihkan dengan aquadest. Diulangi dengan cara kerja yang sama dengan menggunakan larutan dapar phosfat (pH 6,8) semua tablet harus hancur menyeluruh dalam waktu 1 jam.

Syarat : waktu hancur tidak boleh hancur dalam 60 menit dalam medium asam. Dan harus segera hancur dalam medium basa. Bila 1 tablet atau 2 tablet tidak hancur sempurna, ulangi pengujian dengan 12 tablet lainnya, tidak kurang dari 16 dari 18 tablet yang harus diuji harus hancur sempurna (Anonim, 2014).

\section{Analisa Data}

Data yang diperoleh dari penelitian ini ditampilkan secara deskriptif dalam bentuk tabel dan dibandingkan dengan persyaratan yang tertera di Farmakope Indonesia atau literatur resmi lainnya.

\section{HASIL DAN PEMBAHASAN}

Penelitian ini dilakukan untuk melihat perbedaan sifat fisik dari 3 sampel tablet salut enterik kalium diklofenak generik dan generik bermerek dari pabrik berbeda, nomor batch dan tanggal kadaluarsanya yang sama yamg beredar di Kecamatan Siak Hulu. Hal ini dilakukan karena suatu pabrik yang memproduksi obat harus menjamin mutu, khasiat, dan keamanan produk obat yang dihasilkan, agar sesuai dengan tujuan penggunaan, memenuhi persyaratan izin edar sehingga tidak membahayakan pasien (Hutabarat, 2006).

Pada penelitian ini, 3 jenis tablet Kalium diklofenak $50 \mathrm{mg}$ diberi kode yaitu untuk 2 tablet generik diberi kode $\mathrm{A}$ dan $\mathrm{B}$, kemudian untuk 1 tablet generik bermerek diberi kode C. Ketika dibuka, tablet tersebut langsung diuji. Pengujian mutu fisik dilakukan berturut-turut setelah tablet dibuka dari kemasannya. Evaluasi yang dilakukan seperti keseragaman ukuran, kekerasan, kerapuhan, ketahanan, keseragaman bobot dan waktu hancur.

Keseragaman ukuran dilakukan untuk memastikan bahwa tablet mempunyai ketebalan dan diameter yang seragam. Ukuran dan bentuk tablet dapat dievaluasi dan dikontrol dengan mengukur dimensi dari tablet. Dimensi yang berpengaruh pada proses adalah ketebalan (Syukri, 2018). Alat yang digunakan untuk mengukur diameter dan ketebalan dari masing-masing tablet adalah jangka sorong (Siregar, 2010).

Pada uji keseragaman ukuran tablet, didapatkan hasil diameter rata-rata dari tablet Kalium diklofenak generik $\mathrm{A}$ dan $\mathrm{B}$, dan generik bermerek $\mathrm{C}$ memenuhi persyaratan menurut Farmakope Indonesia, yaitu diameter tablet tidak kurang dari $1 \frac{1}{2}$ dan tidak boleh lebih dari 3 kali tebal tablet (Anonim, 1979). Tablet kalium diklofenak generik yang diuji Tablet A memiliki diameter rata-rata sebesar $0,82 \mathrm{~cm}$ dan rata-rata ketebalannya sebesar $0,49 \mathrm{~cm}$ dan tablet $\mathrm{B}$ diameter rata-ratanya sebesar $0,83 \mathrm{~cm}$ dan ketebalan rata-ratanya sebesar 0,37 cm. Tablet kalium diklofenak generik bermerek yang diuji tablet $\mathrm{C}$ memiliki diameter rata-rata $0,83 \mathrm{~cm}$ dan ketebalan rata-ratanya $0,49 \mathrm{~cm}$.

Tabel 1. Data Uji Keseragaman Ukuran Tablet Kalium Diklofenak

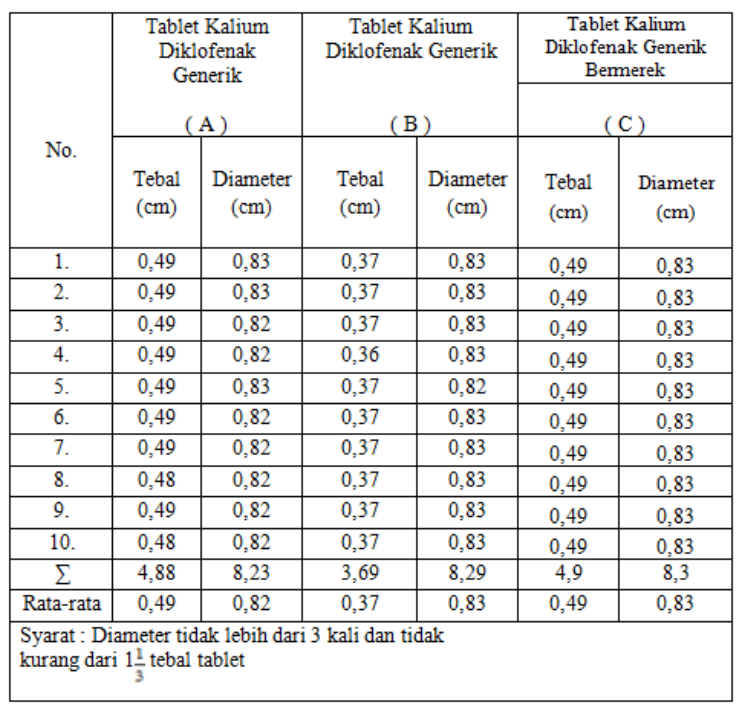

Dari hasil yang diperoleh, maka dapat dinyatakan bahwa tablet kalium diklofenak generik A dan B, dan generik bermerek produk $\mathrm{C}$ memenuhi persyaratan ukuran tablet yang tertera pada farmakope edisi III. Ketebalan tablet dipengaruhi oleh tekanan kompresi, pengisian ke dalam lobang cetakan, dan distribusi ukuran partikel. Pengujian keseragaman ukuran ini penting untuk dilakukan, karena keseragaman ukuran merupakan tahap awal pengujian tablet, jika suatu tablet memiliki tebal dan diameter yang seragam, maka diharapkan tablet tersebut juga memiliki bobot dan kadar zat aktif yang seragam (Syukri, 2018).

Mengukur kekerasan tablet, menggunakan alat hardness tester (stokes monsato). Suatu tablet harus memiliki kekerasan tertentu, agar dapat bertahan terhadap guncangan mekanik pada saat pembuatan, pengepakan, serta berkaitan dengan waktu hancur dan untuk kekerasan tablet lepas tunda yaitu antara 10-20 $\mathrm{kg} / \mathrm{cm}^{2}$ (Hadisoewignyo dan Fudholi, 2016).

Bobot rata-rata tablet kalium diklofenak generik yang diuji adalah $0,207 \mathrm{~g}$ untuk tablet $\mathrm{A}$ dan tablet $\mathrm{B} 0,226 \mathrm{~g}$, Bobot rata-rata tablet kalium diklofenak generik bermerek yang diuji tablet C 0,213 g. Dari hasil yang diperoleh, kekerasan tablet kalium diklofenak generik A memiliki rata-rata $10,3 \mathrm{~kg} / \mathrm{cm}^{2}$ dan tablet B memiliki rata-rata $10,2 \mathrm{~kg} / \mathrm{cm}^{2}$, untuk tablet kalium diklofenak generik bermerek tablet $\mathrm{C}$ memiliki rata-rata $11,6 \mathrm{~kg} / \mathrm{cm}^{2}$. Dari ketiga produk tablet memiliki rata-rata kekerasan yang memenuhi persyaratan, yaitu antara $10-20 \mathrm{~kg} / \mathrm{cm}^{2}$. 
Tabel 2. Data Hasil Uji Kekerasan Tablet Kalium Diklofenak

\begin{tabular}{|c|c|c|c|}
\hline \multirow{3}{*}{ No. } & \multicolumn{3}{|c|}{ Kekerasan $\left(\mathrm{Kg} / \mathrm{cm}^{2}\right)$} \\
\hline & $\begin{array}{c}\text { Tablet } \\
\text { Kalium } \\
\text { Diklofenak } \\
\text { Generik }\end{array}$ & $\begin{array}{c}\text { Tablet } \\
\text { Kalium } \\
\text { Diklofenak } \\
\text { Generik }\end{array}$ & $\begin{array}{c}\text { Tablet Kalium } \\
\text { Diklofenak } \\
\text { Generik } \\
\text { Bermerek }\end{array}$ \\
\hline & (A) & (B) & (C) \\
\hline 1. & 11 & 10 & 10 \\
\hline 2. & 10 & 10 & 11 \\
\hline 3. & 10 & 11 & 12 \\
\hline 4. & 10 & 10 & 12 \\
\hline 5. & 10 & 10 & 12 \\
\hline 6. & 10 & 10 & 12 \\
\hline 7. & 10 & 10 & 12 \\
\hline 8. & 11 & 11 & 11 \\
\hline 9. & 11 & 10 & 12 \\
\hline 10. & 10 & 10 & 12 \\
\hline$\Sigma$ & 103 & 102 & 116 \\
\hline Rata-rata & 10,3 & 10,2 & 11,6 \\
\hline Kesimpulan & $\begin{array}{l}\text { Memenuhi } \\
\text { persyaratan }\end{array}$ & $\begin{array}{l}\text { Memenuhi } \\
\text { persyaratan }\end{array}$ & $\begin{array}{l}\text { Memenuhi } \\
\text { persyaratan }\end{array}$ \\
\hline \multicolumn{4}{|c|}{$\begin{array}{l}\text { Syarat: Tablet lepas tunda kekerasan antara } \\
10-20 \mathrm{~kg} / \mathrm{cm} 2\end{array}$} \\
\hline
\end{tabular}

Kekerasan suatu tablet berhubungan dengan persentase friabilitas dan friksibitas, karena jika tablet memiliki kekerasan yang tinggi, maka persentase friabilitas dan friksibitas semakin rendah, begitu juga sebaliknya. Pada umumnya tablet yang keras memiliki waktu hancur yang lama (lebih sukar hancur) dan disolusi yang rendah, namun tidak selamanya demikian. Tetapi biasanya tablet yang tidak keras akan memiliki kerapuhan yang tinggi dan lebih sulit penanganannya pada saat pengemasan, dan transportasi (Roihana, 2008).

Dari hasil yang diperoleh ada kekerasan tablet yang berbeda. Perbedaan kekerasan ini dapat disebabkan karena perbedaan tekanan kompresi yang diberikan pada saat pencetakan tablet. Faktor-faktor yang mempengaruhi kekerasan tablet adalah tekanan kompresi dan sifat bahan yang dikempa. Semakin besar tekanan yang diberikan saat pentabletan akan meningkatkan kekerasan tablet. Peningkatan jumlah bahan pengikat akan meningkatkan kekerasan tablet meskipun tekanan kompresinya sama (Hadisoewignyo dan Fudholi, 2013). Semakin keras suatu tablet akan semakin baik, asal waktu hancur dan disolusinya memenuhi persyaratan (Syukri, 2018).

Uji friabilitas (Kerapuhan), kerapuhan dinyatakan sebagai masa seluruh partikel dilepaskan dari tablet akibat adanya beban pengujian mekanis yang dinyatakan dalam persen (\%) yang mengacu pada masa tablet awal sebelum pengujian dari tablet kalium diklofenak Uji friabilitas merupakan gambaran lain dari ketahanan dalam melawan pengikisan dan guncangan terhadap tablet. Uji kerapuhan berhubungan dengan kehilangan bobot akibat abrasi yang terjadi pada permukaan tablet (Hadisoewignyo dan Fudholi, 2013). Untuk hasil yang baik, maka persentase friabilitas dan friksibilitas yang didapat tidak boleh lebih dari $1 \%$, kerapuhan tablet dapat diuji dengan alat uji kerapuhan friability tester (Lachman, 1994).

Hasil dari uji kerapuhan tablet produk A, B, dan $\mathrm{C}$ memenuhi persyaratan. Tablet A memiliki persentase friabilitas sebesar $0,86 \%$, tablet B memiliki persentase friabilitas sebesar $0,83 \%$, dan Tablet $\mathrm{C}$ memiliki persentase friabilitas sebesar 0,19. Karena semakin besar kekerasan tablet maka semakin kecil kerapuhan tablet. Semakin besar persentase friabilitas, maka semakin besar massa tablet yang hilang, sehingga kadar zat dalam tablet akan berkurang dan waktu hancur tablet akan semakin cepat (Sulaiman, 2007). Kerapuhan yang tinggi akan mempengaruhi kadar zat aktif yang ada pada tablet (Hadisoewignyo dan Fudholi, 2013).

Tabel 3. Data Hasil Uji Kerapuhan Tablet Kalium Diklofenak

\begin{tabular}{|c|c|c|c|c|c|}
\hline \multirow[b]{2}{*}{ No } & \multirow[b]{2}{*}{ Sampel } & \multicolumn{2}{|c|}{ Berat (g) } & \multirow{2}{*}{$\begin{array}{c}\% \\
\text { Friabilitas }\end{array}$} & \multirow[b]{2}{*}{ Kesimpulan } \\
\hline & & $\begin{array}{l}\text { Awal } \\
\text { (Wo) }\end{array}$ & $\begin{array}{l}\text { Akhir } \\
\text { (Wt) }\end{array}$ & & \\
\hline 1. & $\begin{array}{c}\text { Tablet } \\
\text { Kalium } \\
\text { Diklofenak } \\
\text { Generik } \\
\text { (A) }\end{array}$ & 4,394 & 4,356 & $0,86 \%$ & $\begin{array}{l}\text { Memenuhi } \\
\text { persyaratan }\end{array}$ \\
\hline 2. & $\begin{array}{c}\text { Tablet } \\
\text { Kalium } \\
\text { Diklofenak } \\
\text { Generik } \\
\text { (B) }\end{array}$ & 4,784 & 4,744 & $0,83 \%$ & $\begin{array}{l}\text { Memenuhi } \\
\text { persyaratan }\end{array}$ \\
\hline 3. & $\begin{array}{c}\text { Tablet } \\
\text { Kalium } \\
\text { Diklofenak } \\
\text { Generik } \\
\text { Bermerek } \\
\text { (C) }\end{array}$ & 4,530 & 4,521 & $0,19 \%$ & $\begin{array}{l}\text { Memenuhi } \\
\text { persyaratan }\end{array}$ \\
\hline
\end{tabular}

Selanjutnya, uji friksibilitas (ketahanan) tablet berhubungan gesekan antara sesama tablet tersebut disebut friksibility. Alat yang digunakan dalam pengujian ini disebut abration tester. Hasil dari uji friksibilitas tablet produk $\mathrm{A}, \mathrm{B}$, dan $\mathrm{C}$ memenuhi persyaratan. Tablet A memiliki persentase friksibilitas sebesar $0,13 \%$, Tablet B memiliki persentase friabilitas sebesar $0,35 \%$, dan Tablet $\mathrm{C}$ memiliki persentase friabilitas sebesar 0,04 .

Dari hasil penelitian dapat dilihat adanya perbedaan persentase friksibilitas setiap tablet. Tablet generik A memiliki persentase friksibilitas lebih rendah dari tablet generik $\mathrm{B}$ dan tablet generik bermerek $\mathrm{C}$ lebih rendah persentase friksibilitasnya dari tablet generik, karena semakin besar kekerasan tablet maka semakin kecil persentase ketahanan tablet (Siregar, 2010). Semakin besar persentase friabilitas dan friksibilitas, maka semakin besar massa tablet yang hilang, sehingga kadar zat dalam tablet akan berkurang dan waktu hancur tablet akan semakin cepat (Lestari, 2013). 
Tabel 4. Data Hasil Uji Ketahanan Tablet Kalium Diklofenak

\begin{tabular}{|c|c|c|c|c|c|}
\hline \multirow[b]{2}{*}{ No } & \multirow[b]{2}{*}{ Sampel } & \multicolumn{2}{|c|}{ Berat (g) } & \multirow{2}{*}{$\begin{array}{c}\% \\
\text { Friksibilitas }\end{array}$} & \multirow[b]{2}{*}{ Kesimpulan } \\
\hline & & $\begin{array}{l}\text { Awal } \\
\text { (Wo) }\end{array}$ & $\begin{array}{l}\text { Akhir } \\
\text { (Wt) }\end{array}$ & & \\
\hline 1. & $\begin{array}{c}\text { Tablet } \\
\text { Kalium } \\
\text { Diklofenak } \\
\text { Generik } \\
\text { (A) }\end{array}$ & 4,364 & 4,358 & $0,13 \%$ & $\begin{array}{l}\text { Memenuhi } \\
\text { persyaratan }\end{array}$ \\
\hline 2. & $\begin{array}{c}\text { Tablet } \\
\text { Kalium } \\
\text { Diklofenak } \\
\text { Generik } \\
\text { (B ) }\end{array}$ & 4,754 & 4737 & $0,35 \%$ & $\begin{array}{l}\text { Memenuhi } \\
\text { persyaratan }\end{array}$ \\
\hline 3. & $\begin{array}{c}\text { Tablet } \\
\text { Kalium } \\
\text { Diklofenak } \\
\text { Generik } \\
\text { Bermerek } \\
\text { (C) }\end{array}$ & 4,515 & 4,513 & $0,04 \%$ & $\begin{array}{l}\text { Memenuhi } \\
\text { persyaratan }\end{array}$ \\
\hline & Syarat : K & hanan & $\mathrm{ng}$ ba & dak melebih & \\
\hline
\end{tabular}

Uji keseragaman bobot dapat mempengaruhi ketepatan takaran, kandungan bahan aktif setiap tablet (Voight, 1995), tujuan pengujian keseragaman bobot ini untuk mengontrol mutu tablet yang merupakan indikator awal keseragaman kadar zat aktif. Tablet yang memiliki bobot yang seragam diharapkan memiliki kadar zat aktif yang seragam pula (Sulaiman, 2007). Hasil bobot ratarata pengujian tablet kalium diklofenak generik tablet $\mathrm{A}$ adalah 0,207 $\mathrm{g}$ dan tablet $\mathrm{B}$ adalah 0,226 g, tablet kalium diklofenak generik bermerek tablet $\mathrm{C}$ adalah 0,213 g. Pengujian pertama dilakukan 10 Tablet Kalium diklofenak Generik dan generik bermerek, Persyaratan menurut Farmakope Indonesia IV dari keseragaman dosis dipenuhi jika jumlah zat aktif dalam masingmasing dari 10 sediaan dianggap memenuhi syarat jika keseragaman bobot terletak dalam rentang $85,0 \%$ hingga $115,0 \%$ dan simpangan baku relatif dari 10 satuan sediaan kecil atau sama dengan 6,0\% (Anonim, 1995).

Jika ada 1 sediaan terletak diluar jarak $85,0 \%$ hingga $115,0 \%$ tetapi tidakdiluar rentang $75,0 \%$ hingga $125,0 \%$, atau jika simpangan baku relatif lebih besar dari $6,0 \%$ atau jika kedua kondisi gagal, pengujian dilakukan terhadap 20 satuan tambahan. Persyaratan dipenuhi tidak lebih dari 1 dari 20 Tablet terletak diluar rentang $85,0 \%$ hingga $115,0 \%$, dan tidak ada satuan diluar rentang 75,0 hingga $125,0 \%$, dan simpangan baku relatif dari 30 satuan sediaan tidak lebih dari 7,8\%. Maka tablet Kalium generik A, B, dan C memenuhi persyaratan, karena tidak ada satu tabletpun yang bobotnya kurang dari $85,0 \%$ dan tidak ada satu tabletpun yang bobot nya lebih dari $115,0 \%$. Simpangan baku relatif tablet kalium diklofenak $\mathrm{A}, \mathrm{B}$, dan $\mathrm{C}$ tidak lebih dari $6,0 \%$, sehingga ke 3 sampel tablet kalium diklofenak yang telah diuji dianggap memenuhi persyaratan keseragaman bobot.
Tabel 5. Data Hasil Uji Keseragaman Bobot Tablet Kalium Diklofenak

\begin{tabular}{|c|c|c|c|c|c|c|}
\hline \multirow[b]{2}{*}{ No. } & \multicolumn{2}{|c|}{$\begin{array}{c}\text { Tablet Kalium } \\
\text { Diklofenak } \\
\text { Generik } \\
\text { (A) }\end{array}$} & \multicolumn{2}{|c|}{$\begin{array}{c}\text { Tablet Kalium } \\
\text { Diklofenak } \\
\text { Generik } \\
\text { (B) }\end{array}$} & \multicolumn{2}{|c|}{$\begin{array}{c}\text { Tablet Kalium } \\
\text { Diklofenak Generik } \\
\text { Bermerek } \\
\text { (C) }\end{array}$} \\
\hline & $\begin{array}{c}\text { Bobot } \\
1 \\
\text { tablet } \\
(\mathrm{g})\end{array}$ & $\begin{array}{l}\text { Memenuhi } \\
\text { persyaratan } \\
\text { (M) / (TM) }\end{array}$ & $\begin{array}{c}\text { Bobot } \\
1 \\
\text { tablet } \\
(\mathrm{g})\end{array}$ & $\begin{array}{l}\text { Memenuhi } \\
\text { persyaratan } \\
\text { (M) / (TM) }\end{array}$ & $\begin{array}{c}\text { Bobot } \\
1 \\
\text { tablet } \\
\text { (g) }\end{array}$ & $\begin{array}{l}\text { Memenuhi } \\
\text { persyaratan } \\
\text { (M)/(TM) }\end{array}$ \\
\hline 1. & 0,201 & $\mathrm{M}$ & 0,219 & M & 0,212 & M \\
\hline 2. & 0,204 & $\mathrm{M}$ & 0,228 & M & 0,218 & M \\
\hline 3. & 0,206 & M & 0,223 & M & 0,211 & M \\
\hline 4. & 0,215 & $\mathrm{M}$ & 0,221 & $\mathrm{M}$ & 0,217 & $\mathrm{M}$ \\
\hline 5. & 0,208 & $\mathrm{M}$ & 0,236 & $\mathrm{M}$ & 0,209 & M \\
\hline 6. & 0,204 & M & 0,229 & M & 0,21 & M \\
\hline 7. & 0,206 & $\mathrm{M}$ & 0,225 & $\mathrm{M}$ & 0,213 & $\mathrm{M}$ \\
\hline 8. & 0,207 & $\mathrm{M}$ & 0,224 & $\mathrm{M}$ & 0,213 & M \\
\hline 9. & 0,207 & $\mathrm{M}$ & 0,225 & M & 0,219 & $\mathrm{M}$ \\
\hline 10. & 0,208 & M & 0,228 & M & 0,208 & M \\
\hline$\Sigma$ & & 2,066 & & 2,258 & & 2,13 \\
\hline Rata-rata & & 0,207 & & 0,226 & & 0,213 \\
\hline $85 \%$ & & 0,176 & & 0,192 & & 0,181 \\
\hline $115 \%$ & & 0,238 & & 0,260 & & 0,245 \\
\hline SD & & 0,004 & & 0,005 & & 0,004 \\
\hline SBR & & 1,770 & & 2,117 & & 1,798 \\
\hline
\end{tabular}

Pengujian terakhir yang dilakukan adalah uji waktu hancur tablet. Waktu hancur adalah waktu yang dibutuhkan sejumlah tablet untuk hancur menjadi granul/partikel penyusunnya (Hadisoewignyo dan Fudholi, 2016). Waktu hancur merupakan persyaratan untuk terjadinya disolusi. Tablet mula-mula akan hancur kemudian zat aktif terlepas, terdisolusi, diserap dan didistribusikan ketempat kerjanya (Aini, 2013). Pengujian Waktu hancur tablet salut enterik Kalium diklofenak menggunakan cairan penganti asam lambung HCL 0,06 N pengerjaan dilakukan selama 1 jam, tablet tidak larut kecuali zat penyalut. Angkat keranjang, tablet segera dicuci dengan aquadest. Larutan asam diganti dengan larutan dapar $\mathrm{pH} 6,8$ atur suhu $\pm 37^{\circ}$, dilanjutkan pengujian selama 60 menit pada akhir pengujian tidak terdapat bagian tablet kecuali fragmen zat penyalut.

Dari pengamatan yang dilakukan tablet A, B, dan C memenuhi persyaratan karena tidak lebih dari 60 menit (Anonim, 1995). Tetapi terdapat perbedaan yang signifikan untuk uji waktu hancur antara sampel tablet kalium diklofenak generik dan generik bermerek, pada tablet kalium diklofenak generik Tablet A dan B memiliki waktu hancur rata-rata sampel A 13 Menit 55 detik, Tablet B tablet 11 Menit 07 detik, sedangkan tablet kalium diklofenak generik bermerek $\mathrm{C}$ memiliki waktu hancur rata-rata 25 menit 04 detik.

Salah satu penyebab perbedaan yang signifikan dari waktu hancur tablet ialah dari formulasi yang digunakan. Jika kekerasan tablet berubah, maka akan mempengaruhi waktu hancur dan kecepatan disolusi tablet tersebut (Widodo, 2004). 
Tabel 6. Data Hasil Uji Waktu Hancur Tablet Kalium Diklofenak

\begin{tabular}{|c|c|c|c|c|c|c|}
\hline \multirow{3}{*}{ No. } & \multicolumn{6}{|c|}{ Waktu hancur tablet } \\
\hline & \multicolumn{2}{|c|}{$\begin{array}{c}\text { Tablet kalium } \\
\text { diklofenak generik } \\
\text { (Tablet A) }\end{array}$} & \multicolumn{2}{|c|}{$\begin{array}{c}\text { Tablet kalium } \\
\text { diklofenak generik } \\
\text { (Tablet B) }\end{array}$} & \multicolumn{2}{|c|}{$\begin{array}{c}\text { Tablet kalium } \\
\text { diklofenak generik } \\
\text { bermerek } \\
\text { (Tablet C) }\end{array}$} \\
\hline & Menit & Detik & Menit & Detik & Menit & Detik \\
\hline 1. & 14 & 35 & 12 & 13 & 30 & 35 \\
\hline 2. & 11 & 30 & 5 & 21 & 25 & 08 \\
\hline 3. & 12 & 33 & 8 & 58 & 24 & 45 \\
\hline 4. & 13 & 35 & 11 & 50 & 21 & 23 \\
\hline 5. & 15 & 15 & 5 & 40 & 22 & 17 \\
\hline 6. & 12 & 05 & 9 & 40 & 24 & 16 \\
\hline Rata-rata & 13 & 55 & 11 & 07 & 25 & 04 \\
\hline Kesimpulan & \multicolumn{2}{|c|}{$\begin{array}{l}60 \text { Menit } \\
\text { (Memenuhi } \\
\text { persyaratan) }\end{array}$} & \multicolumn{2}{|c|}{$\begin{array}{l}<60 \text { Menit } \\
\text { Memenuhi } \\
\text { persyaratan }\end{array}$} & \multicolumn{2}{|c|}{$\begin{array}{l}<60 \text { Menit } \\
\text { Memenuhi } \\
\text { persyaratan }\end{array}$} \\
\hline & & & yarat : & ak lebih & $60 \mathrm{me}$ & \\
\hline
\end{tabular}

\section{SIMPULAN}

Dari hasil penelitian yang telah dilakukan terhadap 3 produk tablet kalium diklofenak generik dan generik bermerek, dapat disimpulkan bahwa semua tablet pada uji sifat fisik tablet yaitu keseragaman ukuran, kekerasan tablet, uji kerapuhan, uji ketahanan, uji keseragaman bobot dan uji waktu hancur memenuhi persyaratan menurut Farmakope Indonesia edisi IV dan literatur resmi lainnya.

\section{SARAN}

Untuk peneliti selanjutnya agar dapat melakukan uji disolusi tablet kalium diklofenak untuk mengukur absorbansinya dan untuk menentukan jumlah obat terlarut dalam selang waktu tertentu.

\section{DAFTAR PUSTAKA}

Aini, N., Saraswati. R. D., Oktaberia I. A. 2015. Profil Disolusi Terbanding, Penetapan Kadar, dan Kualitas Fisik Tablet Atorvastatin Inovator, Generik Bernama Dagang, dan Generik. Jurnal Kefarmasian Indonesia, Volume 5 Nomor 2, Hal. 9097.

Anonim. 1979. Farmakope Indonesia. Edisi III. Jakarta: Departemen Kesehatan Republik Indonesia.

Anonim. 1995. Farmakope Indonesia.Edisi IV. Jakarta: Departemen Kesehatan Republik Indonesia.
Anonim. 2007. Farmakologi dan Terapi. edisi 5. Departemen Farmakologi Terapeutik, Fakultas Kedokteran. Universitas Indonesia.

Chaerunisaa, A.Y., Surahman, E., Imron, S.S. 2009. Farmasetika Dasar Konsep Teoritis dan Aplikasi Pembuatan Obat. Padjajaran: Widya Padjajaran.

Goodman and Gilman, 2007. Dasar Farmakologi Terapi. Edisi 10 Vol.2, Diterjemahkan Oleh Tim Bahasa Sekolah Farmasi ITB, Penerbit Buku Kedokteran ECG. Jakarta.

Hadisoewignyo, L., dan Fudholi, A. 2013. Sediaan Solid. Yogyakarta: Pustaka Pelajar.

Hadisoewignyo, L., dan Fudholi, A. 2016. Sediaan Solid. Yogyakarta: Pustaka Pelajar.

Hutabarat, F. C. R. 2006. Pemastian Mutu Obat : Kompendium Pedoman \& Bahan-Bahan Terkait GMP dan Inspeksi. Edisi II. Jakarta : EGC.

Lachman, L., Lieberman, H.A., dan Kanig, J.L. 1994. Teori dan Praktek Farmasi Industri II. Edisi III. Jakarta: UI Press.

Lestari, N. 2013. Pengaruh Kondisi Penyimpanan Obat Terhadap Kualitas Tablet Vitamin C di Puskesmas Kecamatan Pontianak Kota,Skripsi,Fakultas Kedokteran Universitas Tanjungpura, Pontianak.

Masruriati, 2013. Perbandingan Karakteristik Fisik dan Kadar Zat Aktif Natrium Diklofenak pada Tablet Generik dan Tablet Dengan Nama Dagang. Kendal : Sekolah Tinggi Ilmu Kesehatan.

Roihana, D. H. 2008. Perbandingan Avaibilitas In Vitro Tablet Metronidazol Produk Generik dan Dagang, Skripsi, Universitas Muhammadiyah, Surakarta.

Sambara, J 2007. Profil dan Tinjauan Penggunaan Obat generik Di Rumah Sakit Umum Daerah Prof.Dr.W.Z. Johannes Kupang.

Shargel, L. and Yu. 2005.Biofarmasetika dan Farmakokinetika Terapan, Edisi Kedua, Airlangga University Press, Surabaya. 167-187.

Siregar, C. J. 2010. Teknologi Farmasi Sediaan Tablet. Jakarta: EGC.

Sulaiman, T. N. S. 2007. Teknologi dan Formulasi Sediaan Tablet. Yogyakarta: Gadjah Mada University Press.

Syukri, Yandi. 2018. Teknologi Sediaan Obat dalam Bentuk Solid. Yogyakarta: Universitas Islam Indonesia.

Voigt, R. 1995. Buku Pelajaran Teknologi Farmasi. Yogyakarta: Gadjah Mada University Press.

Widodo, R. 2004. Panduan Keluarga Memilih dan Menggunakan Obat.Yogyakarta : Kreasi Wacana. 